\title{
Factors associated with mothers' knowledge on infant and young child feeding recommendation in slum areas of Bahir Dar City, Ethiopia: cross sectional study
}

Yeshalem Mulugeta Demilew*

\begin{abstract}
Background: Malnutrition is a public health concern in Ethiopia. This might be correlated with inappropriate infant and young child feeding practice. This in turn is affected by Mothers' knowledge on feeding practice. However, information on mothers' knowledge on infant and young child feeding recommendation was scarce in Ethiopia. Therefore, this study was designed to assess mothers' knowledge on infant and young child feeding recommendation and associated factors in slum areas of Bahir Dar City, Ethiopia.

Methods: A community based cross-sectional study was conducted from May 1-26/2015. Systematic sampling technique was used to select respondents. Data were collected by pretested, structured, interviewer administered questionnaire. Data were entered and analyzed by SPSS version 20 software. Knowledge score was computed. Binary and multivariable logistic regression analysis were used to identify factors associated with maternal knowledge.

Results: Only $28.7 \%$ of mothers had sufficient knowledge on infant and young child feeding recommendation. Factors associated with mothers, knowledge were above primary education [AOR 2.5, 95\% Cl $(1.5,3.9)]$, possession of radio $[A O R$ 1.7, $95 \% \mathrm{Cl}(1.1,2.7)]$, attending antenatal care $[\mathrm{AOR} 2.4,95 \% \mathrm{Cl}(1.5,4.0)]$, and having employed husband [AOR 2.3, 95\% Cl $(1.2,4.4)]$.

Conclusion: Mothers'knowledge on infant and young child feeding recommendation was very low. Hence, education on infant and young child feeding recommendation should be strengthened during antenatal care visit and using mass media especially for mothers with lower educational status to fill up of this gap.
\end{abstract}

Keywords: Mothers, Knowledge, Slum, Ethiopia

\section{Background}

In developing countries, malnutrition continues to be a major contributor to childhood morbidity and mortality. Thus, it adversely affects individuals, family and the community at large $[1,2]$. Primarily, malnutrition occurs during the first 2 years of life as children have high demand for nutrients to support rapid growth and development; are more susceptible to infection; have heightened sensitivity to biological programming and are totally

${ }^{*}$ Correspondence: yeshalem_mulugeta@yahoo.com School of Public Health, College of Medicine and Health Sciences, Bahir Dar University, P.O. Box 79, Bahir Dar, Ethiopia dependent on others for nutrition, care and social interactions [3]. Hence, the first 2 years of life is considered as a critical window of opportunity to address malnutrition [4].

From all proven preventive health and nutrition interventions infant and young child feeding (IYCF) has greatest potential impact on child survival [5]. Reduction of child morbidity and mortality can be reached only when IYCF practices are properly implemented to ensure adequate nutrition during early child hood period [6-8]. Despite strong evidence on benefit of IYCF, inappropriate IYCF practices have been widely documented in low- and middle-income countries [9-15]. 
Ethiopian government developed and implemented the Infant and Young Child Feeding (IYCF) guideline in 2004 to improve feeding practice [16]. Based on the guideline IYCF messages were given at health institution and community level. However, majority of mothers inappropriately fed their children [17-20]. Urban slum dwellers are illiterate with low socioeconomic status, and lack of access to basic health care facilities which further affect IYCF practice $[21,22]$.

Knowledge of the mother on IYCF recommendation has statistically significant association with their IYCF practice. Mothers who have insufficient knowledge on IYCF recommendation were more likely to have inappropriate IYCF practice [23, 24]. Even, inadequate knowledge is often an important determinant of care givers feeding practice than availability of food $[6,25]$. Nevertheless, the rate of knowledge on IYCF recommendation differed across countries. Previous studies in various countries such as Zambia, Nigeria and Ghana have shown different level of mothers' knowledge on IYCF recommendations [25-27].

Several factors affect mothers' knowledge on IYCF recommendation. These factors include working status of the mother, family size, educational and marital status of the mother, age and sex of the child [2]. Even though, we have seen that different factors affect knowledge of the mother. Nonetheless, there are two rationales to conduct the study in slum sub-cities of Bahir Dar City. Firstly, the researcher hasn't come across prior study in the area. Secondly, knowledge is affected by particular cultures of a given community, which make conducting a study in the target area appropriate. Therefore, this study was conducted to assess the level of mothers' knowledge on IYCF recommendation and associated factors among mothers in slum areas of Bahir Dar City.

\section{Methods}

The study was conducted in slum sub-cities of Bahir Dar City. The City is the capital City of Amhara Regional State, which is found at $565 \mathrm{~km}$ far from Addis Ababa, Northwest Ethiopia. The total population of the City is 288,200 , of which 146,982 were females. According to the Bahir Dar City administration health bureau report, the numbers of under-5-year-old children and children aged 24-36 months were 4345 and 908, respectively. For administrative purpose the City is divided into nine subcities. Among which, three sub-cities are slum (Shumabo, Gish-Abay, and Sefene-selam). Majority of the residents in the slum sub-cities are daily laborers and petty traders.

In the City there are three hospitals (one public Regional referral hospital and one public and one private hospital), 6 health centers, 2 nongovernmental clinics, 9 private special higher clinic, 2 private higher clinics and
12 private clinics to deliver different health care services such as health promotion, prevention, curative and rehabilitative services to the community.

Community based cross-sectional study was conducted among mothers who have 24-36 months old children from May 1-26/2015. The sample size was calculated using Epi-info soft ware version 3.5.2 by considering the following assumptions: 95\% confidence interval, $80 \%$ power, $52 \%$ proportion of knowledge on IYCF, odds ratio to be detected 2, Non-response rate $10 \%$. The final sample size was 495 .

Systematic sampling technique was used to select the study participants. The sample frame was list of mothers who have 24-36 months old children in the slum areas registered by the urban health extension workers. Using this registration logbook the study participants were selected by systematic sampling technique (every other child was selected) considering proportional to size allocation (by considering the number of 24-36 months children's mother) for each slum area. In households with two women with 24-36 months old children, one was selected by lottery method.

Data were collected by pretested, structured interviewer administered questionnaire. The questions were adapted from different literature $[6,8,28]$. Interview with mothers was conducted at their home considering privacy. Three diploma nurses and one public health professional were recruited as a data collector and supervisor respectively.

Mothers' knowledge on IYCF recommendation was assessed by twelve item questions which had yes or no response. A score of one was given for each correct response and zero for wrong response [29]. Mothers who had above six (those who score above average) were leveled as had "sufficient knowledge", whereas, mothers who had six and below were leveled as had "insufficient knowledge" [24].

Data collectors and the supervisor were trained on the purpose of the study, data collection technique and tool before and after pretest. The questionnaire was pretested in slum area near Bahir Dar City and errors were corrected accordingly. Each day, collected information was reviewed and errors were returned to data collectors for correction. The supervisor and investigator closely supervised data collection technique.

Data were entered and analyzed using SPSS version 20. A frequency of each variable was calculated to check for accuracy, outliers, consistency and missed values. Mothers' knowledge on IYCF recommendation was computed. Binary and multivariable logistic regression was done to identify factors associated with mothers' knowledge. $P$ value $\leq 0.2$ was taken as a cut-off point to select variables for the multiple logistic regression models. Place of 
delivery, educational status, educational status of the husband, ANC follow up, occupational status, occupational status of the husband, religion, possession of television and radio were included in the final adjusted model. The model was built with backward elimination to avoid multicollinearity. A P value of less than 0.05 was considered statistical significant.

The study was approved by Ethical review Board of Bahir Dar University. Letter of permission was taken from Bahir Dar City administration health Bureau and sub-city administrators. Verbal consent was taken from participants. Privacy and confidentiality was maintained throughout the study period by excluding personal identifiers from the data collection form.

\section{Results}

\section{Socio demographic characteristics}

Among a total of 495 mothers sampled, 471 were participated, making the response rate of $95.1 \%$. The mean age of the mothers was $30 \pm$ (4.3 SD) years. Majority of the respondents were from Amhara ethnic group, 427 (90.7\%) and orthodox Christian followers, 398 (84.5\%). One hundred fifty-four (32.7\%) mothers and their husbands, 101 (21.4\%) had no formal education. Nearly half of the mothers, $225(47.8 \%)$ and their husbands, 218 $(46.3 \%)$ were housewives and daily laborers respectively (Table 1).

\section{Mothers knowledge of IYCF}

Overall, 135 (28.7\%) mothers had sufficient knowledge on IYCF practice recommendation. Majority of the mothers knew the time of initiation of breast feeding, 432 (91.7\%), the duration of exclusive breast feeding, 397 (84.3\%) and when to switch to the other breast, 379 (80.5\%). However, only few mothers were familiar with frequency of breast feeding per day, 142 (30.1) and total duration of breast feeding, 96 (20.4\%) (Table 2).

Four hundred fourteen (87.9\%) respondents identified exact time of complementary feeding initiation. Even if, majority knew when to start complementary feeding, only a small number of mothers had knowledge on minimum number of complementary food staffs, 64 (13.6), frequency of feeding per day, $146(31 \%)$ and need to increase feeding frequency when age increase, 84 (17.8\%). Besides, only a small number of respondents were familiar about need of iron rich foods, $87(18.5 \%)$ and extra meal during illness, 29 (6.2\%) (Table 2).

\section{Factors associated with mothers' knowledge}

In the binary logistic regression analysis place of delivery, possession of television and radio, educational status of respondents and their husbands, occupational status of mothers and their husbands were statistically associated
Table 1 Socio-demographic characteristics of mothers and their husbands in Slum areas of Bahir Dar City; Ethiopia, May 2015

\begin{tabular}{|c|c|c|}
\hline Variable & Frequency $(n=471)$ & Percentage \\
\hline \multicolumn{3}{|l|}{ Age of the mother (years) } \\
\hline$\leq 24$ & 102 & 21.7 \\
\hline $25-29$ & 207 & 43.9 \\
\hline$\geq 30$ & 162 & 34.4 \\
\hline \multicolumn{3}{|c|}{ Mean $\pm(S D)$ age of their children $=29.65 \pm(4.3)$} \\
\hline \multicolumn{3}{|l|}{ Religion } \\
\hline Orthodox & 398 & 84.5 \\
\hline Muslim & 52 & 11.0 \\
\hline Protestant & 21 & 4.5 \\
\hline \multicolumn{3}{|l|}{ Ethnicity } \\
\hline Amhara & 427 & 90.7 \\
\hline Others* & 44 & 9.3 \\
\hline \multicolumn{3}{|l|}{ Educational status of the mother } \\
\hline Have no formal education & 154 & 32.7 \\
\hline Primary education & 129 & 27.4 \\
\hline Secondary education and above & 188 & 39.9 \\
\hline \multicolumn{3}{|l|}{ Occupational status of the mother } \\
\hline Housewife & 225 & 47.8 \\
\hline Daily laborer & 147 & 31.2 \\
\hline Government employee & 58 & 12.3 \\
\hline Petty trader/private employee & 41 & 8.7 \\
\hline \multicolumn{3}{|l|}{ Marital status of the mother } \\
\hline Married & 404 & 85.8 \\
\hline $\begin{array}{l}\text { Never married/widowed/ } \\
\text { divorced }\end{array}$ & 67 & 14.2 \\
\hline \multicolumn{3}{|l|}{ Educational status of their husband } \\
\hline Have no formal education & 101 & 21.4 \\
\hline Primary education & 110 & 23.4 \\
\hline Secondary education and above & 260 & 55.2 \\
\hline \multicolumn{3}{|l|}{ Occupational status of their husband } \\
\hline Daily laborer & 218 & 46.3 \\
\hline Government employee & 101 & 21.4 \\
\hline $\begin{array}{l}\text { Carpenter/driver/private } \\
\text { employee }\end{array}$ & 152 & 32.3 \\
\hline \multicolumn{3}{|l|}{ Family size } \\
\hline$\leq 4$ & 305 & 64.8 \\
\hline$>4$ & 166 & 35.2 \\
\hline
\end{tabular}

Others $^{*}=$ Agew, Tigry and Oromo

with mothers knowledge on IYCF recommendation (Table 3).

In the multivariable logistic regression analysis, having beyond primary education [AOR 2.5, 95\% CI $(1.5,3.9)$ ], possession of radio [AOR 1.7, 95\% CI $(1.1,2.7)$ ], attending antenatal care [AOR 2.4, 95\% CI $(1.5,4.0)]$, and having employed husband [AOR 2.3, 95\% CI $(1.2,4.4)$ ], were positively associated with mothers knowledge on IYCF recommendation (Table 3). 
Table 2 Knowledge of mothers regarding IYCF practice in Slum areas of Bahir Dar City, Ethiopia, May 2015 $(n=471)$

\begin{tabular}{lcc}
\hline Variable & Frequency & Percenta \\
\hline A neonate should start breastfeeding within 1 h of birth & \\
Yes & 432 & 91.7 \\
No & 39 & 8.3 \\
An infant should exclusively breastfeed for the first 6 months \\
Yes & 397 & 84.3 \\
No & 74 & 15.7 \\
An infant should breast feed at least 8 times/day (on demand but \\
not <8 times) \\
Yes \\
No & 142 & 30.1 \\
An infant should finish one breast milk before switch to other breast \\
Yes & 379 & 80.5 \\
No & 92 & 19.5 \\
An infant should continue breastfeeding until 2 or more years \\
Yes & 96 & 20.4 \\
No & 375 & 79.6 \\
An infant should start complementary foods at 6 months & \\
Yes & 414 \\
No & 57 & 87.9 \\
Abreast feed 6-8 month & 12.1
\end{tabular}

Abreast feed 6-8 months infant should take complementary food 2-3 times/day

$\begin{array}{lll}\text { Yes } & 146 & 31 \\ \text { No } & 325 & 69\end{array}$

A breast feed 9-12 months infant should take complementary food 4 times/day

$\begin{array}{lcc}\text { Yes } & 84 & 17.8 \\ \text { No } & 387 & 82.2 \\ \text { A 6-23 month child need 4 or more food staffs } & \\ \text { Yes } & 64 & 13.6 \\ \text { No } & 407 & 86.4 \\ \text { Non breast feed infant needs extra meal } & \\ \text { Yes } & 314 & 66.7 \\ \text { No } & 157 & 33.3 \\ \text { An infant needs iron-rich foods } & & \\ \text { Yes } & 87 & 18.5 \\ \text { No } & 384 & 81.5 \\ \text { Sick children need extra meal } & & \\ \text { Yes } & 29 & 6.2 \\ \text { No } & 442 & 93.8 \\ \text { Over all knowledge of IYCF } & & \\ \text { Sufficient knowledge } & 135 & 28.7 \\ \text { Insufficient knowledge } & 336 & 71.3 \\ \text { Source of information } & & \\ \text { Health professionals } & 283 & 60.0 \\ \text { Mass media } & 134 & 28.5 \\ \text { Relatives } & 54 & 11.5 \\ & & \end{array}$

\section{Discussion}

Mothers who have sufficient knowledge on IYCF recommendation were more likely to have better feeding practice than mothers who have insufficient knowledge [24, 30,31 . However, in this study only $28.7 \%$ of mothers had sufficient knowledge on IYCF recommendation. Inappropriate knowledge on IYCF recommendation was also reported from previous study finding in Hebei province, North China [29].

On the other hand, this finding was lower than the study findings in Shashemene Woreda, Mekelle, Dehradun District and Nigeria [20, 26, 32, 33]. This discrepancy might be due to time gap between studies and difference in the study settings; since the former studies included mothers in the Woreda with better socio economic characteristics whereas the current study was done among mothers in slum area with lower socio economic status.

Early initiation of breastfeeding plays a crucial role for a significant reduction of neonatal and infant mortality [34, 35]. Besides, it has benefit to the health of the mother as early suckling stimulates the release of prolactin, which helps in the production of milk, and oxytocin, which is responsible for the ejection of milk and stimulates the contraction of the uterus after childbirth [6]. Moreover, initiation of breast feeds within $1 \mathrm{~h}$ of birth is the key for successful breast feeding [36]. Mothers' knowledge on initiation of breast feeding is an important determinant factor for their practice. In the present study majority of the mothers $(91.7 \%)$ knew exact time when to initiate breast feeding after delivery. This finding was better than the study findings in Mizan Aman town, Ethiopia, Nigeria and Nepal [37-39].

Exclusive breast feeding for the first 6 months of life has a significant effect in the reduction of morbidity and mortality as well as to ensure overall development [40]. Despite the well-recognized importance, exclusive breastfeeding practice is not widespread in the developing countries. In the present study, $84.3 \%$ of mothers had knowledge on the need of exclusive breastfeeding for the first 6 months. This finding was better than the study findings in Mizan Aman town, Ethiopia and Andhra Pradesh, India [37, 41]. This might be due to time gap; currently there is nutrition education on IYCF practice through mass media and professionals which has direct contribution to the improvement of maternal knowledge [42].

Continuation of breast feeding up to the age of 2 years or beyond is important as it provides useful amounts of energy, good quality protein and other nutrients essential for brain development [8]. However, in the present study, 
Table 3 Factors associated with mother's knowledge regarding IYCF in Slum areas of Bahir Dar City; Ethiopia, May 2015

\begin{tabular}{|c|c|c|c|c|}
\hline \multirow[t]{2}{*}{ Factor } & \multicolumn{2}{|c|}{ Mothers knowledge on IYCF } & \multirow[t]{2}{*}{$\operatorname{COR}(95 \% \mathrm{c} / \mathrm{l})$} & \multirow[t]{2}{*}{ AOR $(95 \% \mathrm{C} / \mathrm{I})$} \\
\hline & Sufficient & Insufficient & & \\
\hline \multicolumn{5}{|l|}{ Place of delivery } \\
\hline Health institution & $130(27.6)$ & $304(64.5)$ & $2.7(1.0,7.1)$ & \\
\hline Home & $5(1.1)$ & $32(6.8)$ & 1.00 & \\
\hline \multicolumn{5}{|l|}{ Possession of television } \\
\hline Yes & $103(21.9)$ & $192(40.7)$ & $2.4(1.5,3.7)$ & \\
\hline No & $32(6.8)$ & $144(30.6)$ & 1.00 & \\
\hline \multicolumn{5}{|l|}{ Possession of radio } \\
\hline Yes & $76(16.2)$ & $122(25.9)$ & $2.2(1.5,3.3)$ & $1.7(1.1,2.7)$ \\
\hline No & $59(12.5)$ & $214(45.4)$ & 1.00 & 1.00 \\
\hline \multicolumn{5}{|l|}{ Educational status } \\
\hline Less than secondary education & $51(10.8)$ & $104(22.1)$ & 1.00 & 1.00 \\
\hline Secondary and above education & $84(17.8)$ & $232(49.3)$ & $3.6(2.4,5.5)$ & $2.5(1.5,3.9)$ \\
\hline \multicolumn{5}{|l|}{ Educational status of the husband } \\
\hline Less than secondary education & $39(8.3)$ & $172(36.5)$ & 1.00 & \\
\hline Secondary and above education & $96(20.4)$ & $164(34.8)$ & $2.5(1.6,3.9)$ & \\
\hline \multicolumn{5}{|l|}{ ANC follow up } \\
\hline Yes & $105(22.3)$ & $190(40.3)$ & $2.6(1.6,4.2)$ & $2.4(1.5,4.0)$ \\
\hline No & $30(6.4)$ & $146(31.0)$ & 1.00 & 1.00 \\
\hline \multicolumn{5}{|l|}{ Occupational status of the mother } \\
\hline Daily laborer & $25(5.3)$ & $122(25.9)$ & 1.00 & \\
\hline Housewife & $64(13.6)$ & $161(34.2)$ & $1.9(1.1,3.2)$ & \\
\hline Petty traders and government/private employee & $46(9.8)$ & $53(11.2)$ & $4.2(2.3,7.5)$ & \\
\hline \multicolumn{5}{|l|}{ Occupational status of the husband } \\
\hline Daily laborer & $27(5.7)$ & $153(32.5)$ & 1.00 & 1.00 \\
\hline Government employee & $38(8.1)$ & $63(13.4)$ & $3.3(1.9,5.4)$ & $2.3(1.2,4.4)$ \\
\hline Carpenter/driver/private employee & $70(14.8)$ & $120(25.5)$ & $3.4(1.9,6.0)$ & $2.1(1.2,3.6)$ \\
\hline \multicolumn{5}{|l|}{ Religion } \\
\hline Orthodox & $122(25.9)$ & $13(2.8)$ & $2.0(1.0,3.8)$ & \\
\hline Muslim and protestant & $276(58.6)$ & $60(12.7)$ & & \\
\hline
\end{tabular}

$A O R$ adjusted odds ratio, COR crude odds ratio, $95 \% \mathrm{CI}$ ninety-five percent confidence interval

only $20.4 \%$ of mothers knew that breast feeding is to be continued for 2 years or beyond.

In Ethiopia, $10 \%$ of infants under- 6 months are given complementary foods in addition to breast milk and $49 \%$ of children age 6-8 months consume solid, semi-solid, or soft foods. Among breastfed children age 6-23 months, only $4 \%$ receive foods from at least four foods groups (the minimum acceptable diet), while $48 \%$ are fed the minimum number of times or more [2]. In the present study, $87.9 \%$ of mothers knew correct age of introduction of complementary feeds. Knowledge of mothers on frequency and quantity of complementary feeds was very low (17.8 and 13.6\% respectively). This finding was consistent with study finding in Ghana [43]. This low level of knowledge might be due to low attention of participants during nutrition education, often diversity and frequency of complementary food is discussed near the end of education section.
Educational status of the mother had statistically significant association with mothers' knowledge on IYCF practice. Mothers who attained beyond primary education were 2.5 times more likely to have sufficient knowledge than mothers who attained lower than secondary education. Similar finding was reported from previous studies [32, 44-46]. This might be due to the fact that literate mothers understand nutrition information given by the health and nutrition programs.

Having radio was statistically significant factor to improve mothers' knowledge. Mothers who have radio were 1.7 times more likely to have sufficient knowledge than their counter part have no radio. Similar result was reported from a study finding in Arba Minch Zuria [47]. Respondents who have radio were more likely to get nutrition related information from nutrition education given by radio [26]. 
In the study area each woman who comes to the health institution to get immunization service, to attained antenatal and postnatal care is counseled on maternal and child nutrition. In addition to this, in each health facility, theoretical and practical education on IYCF practice is given one times per month during "mothers' day". In this "mothers' day" complementary feeding preparation is demonstrated by health professionals. Moreover, education on IYCF practice is given in the health post to the women who come to get immunization service, to attained antenatal and postnatal care by health extension workers (HEWs). Furthermore, HEWs give nutrition education to all pregnant and lactating women at their home. All these have direct contribution on maternal knowledge. However, according to Ethiopia Mini Demographic and Health Survey done in 2014, 58\% of pregnant women who gave birth in the 5 years preceding the survey received antenatal care for their most recent birth, $34 \%$ from a nurse or midwife, $6 \%$ from a doctor and $18 \%$ of women from a health extension worker. Antenatal care utilization was defined at least one visit of health institution for checkup purpose during the pregnancy of the index child [48].

In this study mothers who had ANC follow up were 2.4 times more knowledgeable than their counter parts who had no ANC follow up. This finding is in agreement with the study finding in northern Ethiopia and Arba Minch Zuria [47, 49]. Mothers who had ANC follow up were more likely to be counseled by professionals on IYCF, which have direct contribution to improve their knowledge level [50]. The fact that this study did not use qualitative information on the guideline to probe their knowledge level and the study includes mothers who have children 24-36 months old are the limitation of this study.

\section{Conclusion and recommendation}

Knowledge of mothers on IYCF practice especially on frequency and type of complementary food, need of iron rich foods and additional foods during illness was very low. Hence, education on IYCF practice should be strengthen by giving emphasis to frequency and type of complementary food, need of iron reach foods, need of additional food during illness and importance of continuing breast feeding up to 2 years by health professionals and through radio can help in filling up of this gap. Improvements should be made in social conditions including literacy, use of radio and major social mobilization endeavors to improve ANC utilization.

\section{Abbreviations}

ANC: Antenatal Care; IYCF: Infant and Young Child Feeding; PNC: Postnatal Care.

\section{Acknowledgements}

I would like to thank study participants who participated in this study and provided valuable information with their full cooperation and Bahir Dar University for its financial support. I am also grateful to express my gratitude to data collectors and supervisors for their time and full commitment.

\section{Competing interests}

The author declare that she has no competing interests.

\section{Availability of data and materials}

If needed the raw data in SPSS is available.

\section{Ethical consideration}

The study was approved by Ethical review Board of Bahir Dar University. Letter of permission was taken from Bahir Dar City administration health Bureau and sub-city administrators. Verbal consent was taken from participants. Privacy and confidentiality was maintained throughout the study period by excluding personal identifiers from the data collection form.

Full name of ethics committee

Mr. Gedefaw Abeje, Mrs. Alemtsehay Mekonnen, Dr. Endalew Gebeyehu, Dr. Belaynew Wassie, Mr. Bay Abera, Dr. Dessalegn Nigatu.

\section{Funding}

This research was funded by Bahir Dar University.

\section{Publisher's Note}

Springer Nature remains neutral with regard to jurisdictional claims in published maps and institutional affiliations.

Received: 5 January 2016 Accepted: 24 May 2017

Published online: 05 June 2017

References

1. Black R, Allen L, Bhutta Z, Caulfield L, Onis M, Ezzati M, et al. Maternal and child under nutrition: global and regional exposures and health consquence. Lancet. 2008;371(9608):243-60.

2. Central Statistical Agency [Ethiopia], ICF International. Ethiopia demographic and health survey 2011. Addis Ababa and Calverton: Central Statistical Agency and ICF International; 2012.

3. Ruel M, Hoddinott J. Investing in early childhood nutrition. International Food Policy Research Institute; 2008. http://www.ifpriorg/publication/ investing-early-childhood-nutrition.

4. UNICEF. Infant and young child feeding. Nutrition section, programmes. New York: UNICEF; 2011

5. World Health Organization. Children: reducing mortality. Fact sheet No 178, Updated September 2013. http://www.who.int/mediacentre/ factsheets/fs178/en/.

6. WHO and UNICEF. Global strategy for infant and young child feeding. Geneva: World Health Organization; 2003.

7. Government of the Federal Democratic Republic of Ethiopia. National Nutrition Programme. June 2013-June 2015, Ethiopia; 2013.

8. World Health Organization. Infant and young child feeding. Model chapter for textbook for medical students and allied health proffesions, France; 2009

9. Michelle C, Thais Tobaruela O, Simone Guerra L, Fabiola Isabel S, Roseli Oselka S. Compelementary feeding: inappropriate practice in infants. J Pediatr. 2010;86(3):196-201.

10. Tagbo B, Ughasoro M. Complmentary feeding pattern of infants attaining the University of Nigeria Teaching Hospital, Ituku, Ozalla, Enugu Nigerian. J Peadiatr. 2009;36(3\&4):51-9.

11. John G, Skella C, James E. Feeding practice and nutritional status in Morongo municipality, Tanzania. Tanzan J Health Res. 2013;15(3):3-7.

12. Happiness S, Abdulsudi I. Persistant child malnutrition in Tanzania: risks associated with traditional complementary food. Afr J Food Sci. 2010:4(11):679-92. 
13. Disha A, Rawat R, Subandoro A, Menom P. Infant and young child feeding practice in Ethiopia and Zambia and their association with child nutrition: analysis of demographic and health survey data. Afr J Food Agric Nutr Dev. 2012;12(2):589-93.

14. Norshahida A, Naleena D. The relationship between maternal education level and feeding practice among children in selected kindergartens in Seangor, Malaysia: cross-sectional survey. Asian J Clin Nutr. 2012;4(2):39-52.

15. Singhal P, Garg S, Chopra H, Jain S, Bajpai S, Kumar A. Status of infant and young child feeding practices with special emphasis on breast feeding in an urban area of Meerut. IOSR J Dent Med Sci. 2013;7(4):7-11.

16. Federal Ministry of Health. National strategy for infant and young child feeding (IYCF). Addis Ababa: Federal Ministry of Health, Family Health Department; 2004.

17. Tewodros A, Jemal $H$, Dereje $H$. Determinants of exclusive breast feeding practice in Ethiopia. Ethiop J Health Dev. 2009;23(1):12-8.

18. Abay S, Dereje B, Worku A, Tesfay T. Determinants of exclusive breast feeding practice among mothers of children age less than six months in Bahir Dar City adminstration, Northwest Ethiopia: a community based cross-sectional study. Sci J Clin Med. 2013;2(6):153-9.

19. Kibebew A. Infant and young child feeding practices among mothers living in Harar, Ethiopia. Harar Bull Health Sci. 2012:4:66-78.

20. Fanos Y, Mekuria A, Mekitie W, Misra A. Infant and young child feeding practice status and associated factors among mothers of under 24-month-old children in Shashemene Woreda, Oromia Region, Ethiopia. Open Access Libr J. 2015;2:e1635. doi:10.4236/oalib.1101635.

21. Alon U. Children's health in slum settings. Arch Dis Child. 2013. doi:10.1136/archdischild-2011-301621.

22. Dipta KM, Apurba S, Asit BS, Akhil BB. Association of child feeding practices with nutritional status of under-two slum dwelling children: a community-based study from West Bengal, India. Indian J Public Health. 2013;57(3):170-2.

23. Sandra G, Gloria EO, Richmond NOA. Child feeding knowledge and practices among women participating in growth monitoring and promotion in Accra, Ghana. BMC Pregnancy Childbirth. 2014;14:180.

24. Gudina E, Yemane B, Alemayehu W. Predictors of non-exclusive breastfeeding at 6 months among rural mothers in east Ethiopia: a communitybased analytical cross-sectional study. Int Breastfeeding J. 2013;8:8. http:// www.internationalbreastfeedingjournal.com/content/8/1/8.

25. Sandra G, Gloria EO, Richmond N. Child feeding knowledge and practices among women participating in growth monitoring and promotion in Accra, Ghana. BMC Pregnancy Childbirth. 2014;14:180.

26. Akeredolu IA, Osisanya JO, Seriki-Mosadolorun JS, Okorafor U. Mothers' nutritional knowledge, infant feeding practices and nutritional status of children (0-24 months) in Lagos State, Nigeria, European. J Nutr Food Saf. 2014:4(4):364-74.

27. Katepa-Bwalya M, Mukonka V, Chipepo C, Masaninga F, Babaniyi O, Siziya S. Infants and young children feeding practices and nutritional status in two districts of Zambia. Int Breastfeed J. 2015. doi:10.1186/ s13006-015-0033-x

28. Ethiopian Minister of Health, USAID. Training of trainers manual for counseling on maternal, infant and young child nutrition; 2011.

29. Wu Q, Scherpbier RW, van Velthoven MH, Chen L, Wang W, Li Y, et al. Poor infant and young child feeding practices and sources of caregivers'feeding knowledge in rural Hebei Province, China: findings from a cross-sectional survey. BMJ Open. 2014;4:e005108. doi:10.1136/ bmjopen-2014-005108.

30. Meenakshi G, Marriyah H, Deeksha K. Infant and young child feeding (IYCF) practices in Udupi district, Karnataka. J Nut Res. 2015;3(1):38-44.

31. Joyce N, Joshua KM. Barriers to infant and child-feeding practices: a qualitative study of primary caregivers in Rural Uganda. J Health Popul Nutr. 2015;33(1):106-16

32. Amanuel B, Gerezgiher BA, Hailemariam B, Kalayou K. Mother's knowledge on nutritional requirement of infant and young child feeding in Mekelle, Ethiopia, cross sectional study. Global J Med Res. 2013:13(6):13-24
33. Vartika S, Ranjeeta K. Infant and young child feeding — knowledge and practices of ASHA workers of Doiwala Block, Dehradun District. Indian J Community Health. 2014;26(1):68-75.

34. Edmond K. Delayed breastfeeding initiation increases risk of neonatal mortality. Pediatrics. 2006;117(3):e380-6.

35. Mullany L. Breastfeeding patterns, time to Initiation and mortality risk among newborns in southern Nepal. J Nutr. 2008;138:599-603.

36. Perez-Escamilla R. Infant feeding policies in maternity wards and their effect on breastfeeding success: an analytical overview. Am J Public Health. 1994;84(1):89-97.

37. Niguse T, Frehiwot H, Dinu A, Eyerus D. Knowledge, attitude and practice towards exclusive breastfeeding among lactating mothers in Mizan Aman town, Southwestern Ethiopia: descriptive crosssectional study. Int Breastfeed J. 2016;11:3. doi:10.1186/s13006-016-0062-0.

38. Sanusi RA, Leshi OO, Agada UN. Mother's knowledge and practice of breastfeeding and complementary feeding in Enugu State, Nigeria. J Res Nurs Midwifery. 2016;5(1):021-9.

39. Joshi S, Barakoti B, Lamsal S. Colostrum feeding: knowledge, attitude and practice in pregnant women in a teaching hospital in Nepal. WebmedCentral: Int J Med Mol Med 2012;3(8):WMC003601.

40. Black R. Maternal and child undernutrition: global and regional exposures and health consequences (Maternal and Child Undernutrition Series 1). Lancet. 2008:37:243.

41. Sujatha P, Prasad K. Knowledge of infant feeding practices among mothers delivered in a tertiary care hospital, Kakinada, East Godavari district, Andhra Pradesh, India. Int J Interdiscip Multidiscip Stud. 2015;2(4):45-9.

42. Zakia R, Fazlur R, Aminur R, Saidur RM. Video show helps in improving IYCF knowledge and practice: experience from rural Bangladesh. South East Asia J Public Health. 2014:4(1):25-9.

43. Gyampoh S, Otoo GE, Aryeetey RN. Child feeding knowledge and practices among women participating in growth monitoring and promotion in Accra, Ghana. BMC Pregnancy Childbirth. 2014;14:180.

44. Ekambaram M, Bhat VB, Ahamed MA. Knowledge, attitiude and practice of breastfeeding among postnatal mothers. Acad J. 2010;14(2):19.

45. Sushma S, Priyanka S, Rashmi T, Nisha P, Mehariya KM. Knowledge, attitude and practices of mothers regarding infant feeding practices. Natl J Med Res. 2013;3(2):147-50.

46. Illyasu Z, Kabir M, Abubakar I, Galadanci N. Current knowledge and practice of exclusive breastfeeding among mothers in Gwale LGA of Kano State. Niger Med Prac. 2005:48(2):50-5.

47. Dessalegn T, Shikur M. Maternal knowledge of optimal breastfeeding practices and associated factors in rural communities of Arba Minch Zuria. Int J Nutr Food Sci. 2013;2(3):122-9. doi:10.11648/j. ijnfs.20130203.15.

48. Central Statistical Agency [Ethiopia]. Ethiopia mini demographic and health survey 2014. Addis Ababa; 2014.

49. Gashaw AB, Amare T, Gizachew AT. Effects of antenatal care and institutional delivery on exclusive breastfeeding practice in northwest Ethiopia: a nested case-control study. Int Breastfeed J. 2015;30:10. doi:10.1186/ s13006-015-0055-4

50. Muhammad OA, Ume S, Umay K, Muhammad I, Usman H. Effect of antenatal counseling on exclusive breastfeeding. J Ayub Med Coll Abbottabad. 2012:24(2):116-9.

\section{Submit your next manuscript to BioMed Central and we will help you at every step:}

- We accept pre-submission inquiries

- Our selector tool helps you to find the most relevant journal

- We provide round the clock customer support

- Convenient online submission

- Thorough peer review

- Inclusion in PubMed and all major indexing services

- Maximum visibility for your research

Submit your manuscript at www.biomedcentral.com/submit 